Schweiz. Z. Tuberk. 1954;11:425

\title{
An die Leser der Schweiz. Zeitschrift für Tuberkulose
}

Die häufige Anwendung der Thorax-Röntgendurchleuchtung ím Sínne einer prophylaktíschen Maßnahme gegenüber der Tuberkulose hat zur Aufdeckung zahlreícher pathologíscher Lungenbefunde geführt, de-ren ätíologísche Abklärung ganz neue Probleme gebracht hat. Die operative Behandlung zahlreícher pathologíscher Lungenprozesse und die anatomische Untersuchung díeser Resektíonsstücke hat ebenfalls gezeígt, daß wír uns heute nícht mehr einseítíg darauf verlassen können, daß die meisten chronísch entzündlíchen Lungenvorgänge tuberkulöser Atíologíe sínd. Es gíbt eî́ne ganze Reíhe chronísch entzündlícher, nícht-tuberkulöser Lungenaffektíonen, die ím Röntgenbíld nícht von der Tuberkulose zu unterscheíden sínd. Die Lungentuberkulose selbst íst, dank der mo-dernen antíbíotíschen und Chemotherapíe, in raschem Rückgang be-gríffen und verlíert allmählích ihre zentrale Stellung ím Rahmen der Lungenerkrankungen. Es erscheínt daher dem Redaktíonskomítee der Schweíz. Zeitschrífi für Tuberkulose angezeígt, díesem Wechsel in der Zusammensetzung der Lungenerkrankungen Rechnung zu tragen und in Zukunft in der Zeítschrift auch Arbeíten zu veròffentlíchen über nícht-tuberkulòse Lungenerkrankungen, die in dífferentíaldíagnostíscher und therapeutíscher Beziehung von ebenso großer Bedeutung sínd. Wír hoffen, damit eínem Bedürfnís der Leserschaft entgegenzukommen und auch den Inhalt der einzelnen Hefte anregender gestalten zu können.

Die Redaktíon der Schweíz. Zeítschrift für Tuberkulose 